\title{
Kavun sineği [Myiopardalis pardalina (Bigot, 1891) (Diptera: Tephritidae)]'nin laboratuvar koşullarında bazı biyolojik parametrelerinin

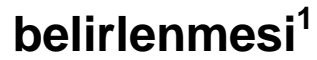

\author{
Some biological parameters for melon fly [Myiopardalis pardalina (Bigot,1891) (Diptera: \\ Tephritidae)] under laboratory conditions
}

Aydemir BARIŞ² Sultan ÇOBANOĞLU

\begin{abstract}
Summary
Melon fly [Myiopardalis pardalina (Bigot, 1891) (Diptera: Tephritidae)] is the most important pest of the melons (Cucumis melo L.) (Cucurbitaceae). Some data related to biological parameters of melon fly were obtained under laboratory condition. For that purpose, the eggs hatching period; the duration of the larval, prepupal and pupal period, the depth of pupation in soil, adult life span and sex ratio were determined. Trials were conducted under laboratory conditions with $16 \mathrm{~h}$ photoperiod at $25 \pm 2{ }^{\circ} \mathrm{C}$ and $65 \%$ humidity. Egg hatching duration was 5.55 days, eggs + larval duration 14.7 days, prepupal stage 3.28 days, pupal stage for females 20.59 days and males 21.5 days. Adult life span was determined for females 11.05 days and for males 8.05 days under laboratory conditions. Pupal stage longevity was determined under two different $50-65 \%$ humidity conditions.
\end{abstract}

Key words: Melon fly, Myiopardalis pardalina, biological parameters, laboratory, different humidity

\section{Özet}

Kavun sineği [Myiopardalis pardalina (Bigot, 1891) (Diptera: Tephritidae)] kavunun (Cucumis melo L.) (Cucurbitaceae) en önemli zararlısıdır. Bu çalışma ile laboratuvar koşullarında zararlının bazı biyolojik parametrelerine ilişkin veriler elde edilmiştir. Bu amaçla Kavun sineğinin yumurta açılım süresi, larva prepupa ve pupa süresi, pupa olduğu derinlikler ile pupaların farklı nem koşullarında açılma süreleri belirlenmiştir. Ayrıca meydana gelen erginlerin dişi-erkek birey oranları ile ergin ömrü tespit edilmiştir. Denemeler sonucunda ortalama olarak yumurta açılma süresi 5.55 gün, yumurta + larva süreleri 14.70 gün, prepupa süresi 3.28 gün, pupa süresi dişilerde 20.59 gün, erkeklerde pupa süresi 21.50 gün, ömür uzunluğu erkekte 8.05, dişide 11.05 gün olarak belirlenmiştir. Denemeler $25 \pm 2{ }^{\circ} \mathrm{C}$ 'li ve $\% 65$ nem içeren 16 saat aydınlatmalı koşullarında yürütülmüştür. Ayrıca pupa döneminin süresi $25 \pm 2{ }^{\circ} \mathrm{C}$ 'li ve $\% 50-65$ olmak üzere iki farklı nem koşullarında çalışılmıştır.

Anahtar sözcükler: Kavun sineği, Myiopardalis pardalina, biyolojik parametre, laboratuar, farklı nem

\footnotetext{
${ }^{1}$ Bu çalışma 26.02.2009'da A. Ü. Fen Bil. Enstitüsünde kabul edilen doktora çalışmasının bir bölümüdür.

2 Zirai Mücadele Merkez Araştırma Enstitüsü Müdürlüğü, Ankara, Türkiye

${ }^{3}$ Ankara Üniversitesi Ziraat Fakültesi Bitki Koruma Bölümü, Ankara, Türkiye

* Sorumlu yazar (Corresponding author) email: aydemirbaris01@gmail.com

Alınış (Received): 05.05.2015 Kabul ediliş (Accepted): 21.07.2015
} 


\section{Giriş}

Kavun (Cucumis melo L., (Cucurbitaceae: Violales) tek yıllık, sıcak ve ılıman iklim bitkisi olup, farklı çevre koşullarına iyi adapte olabilmektedir. FAO verilerine göre dünya kavun üretimi 27 milyon ton düzeyindedir. Türkiye' de kavun üretimi 1.699 .550 ton olup, kavun üretiminde Ankara ili 196.295 ton ile ilk sırada yer almaktadır (Anonymous, 2013).

Kavunun en önemli zararlısı olan Myiopardalis pardalina (Bigot) (Diptera: Tephritidae)'nın da yer aldığı Tephritidae (Diptera) türleri, Solanaceae ve Cucurbitaceae familyası bitkilerinin meyvelerinde zararlıdır. Bu familya içinde pek çok tür konukçusuna özelleşmiş olmakla birlikte bazı türler geniş konukçu dizisine sahiptir (Kapoor et al. 1980; Rauf et al. 2013). Pakistan'da 11 Tephritidae türü saptanmış olup bunlar arasında en yaygın olanları; Bactrocera zonata (Saunders), Bactrocera cucurbitae (Coquillett), Bactrocera dorsalis (Hendel), Myiopardalis pardalina (Bigot, 1891), Carpomya incompleta (Becker, 1903), Carpomya vesuviana Costa, Dacus ferrugineus var. mangiferae Cotes, 1893 ve Dacus diversus Coquillett, 1904 olarak belirlenmiştir (Abdullah \& Latif, 2001; Abdullah et al., 2002; Stonehouse et al., 2002; Panhwar, 2005).

Balucistan Kavun sineği olarak da bilinen M. pardalina Güney Doğu Afrika kökenli olup daha sonra Türkmenistan, ran'a gelmiş, kısa sürede Afganistan, Hindistan ve Pakistan'da yaygın olan zararlı bir tür haline gelmiştir. M. pardalina'nın günümüzde tespit edildiği ülkeler arasında Afganistan, Hindistan, Irak, ran, srail, Kıbrıs, Lübnan, Rusya, Senegal, Suriye ve Türkiye bulunmaktadır (Anonymous, 1961; Freidber \& Kugler, 1989; Stonehouse et al., 2006). Kavun sineği ülkemizde ilk kez Bodenheimer (1941) tarafından belirlenmiştir. Daha sonra zararıının Elazığ, Niğde ve Konya illerinde saptandığını bildirilmiştir (Alkan, 1946). Giray (1961), Kavun sineğinin Elazığ ve çevresinde kabakgillerde zararlı olduğu ve zarar oranının \%60 civarında tespit edildiğini belirtmiştir. Balucistan Kavun sineği, ran'da kavunda önemli bir zararlı olup, kavunlarda yıllık ortalama zarar oranı \% 30-80'e ulaşabilmektedir (EPPO, 2013). M. pardalina larvası meyve içine giriş yaptıktan sonra mücadelesi zor ve başarı şansı çok düşük olan bir türdür. Bu nedenle de zararlı mücadelesine ışık tutabilecek tüm verilerin elde edilmesi önemlidir. Kavun sineğinin yumurta, larva ve pupa süresi ve ergin ömrü sırasıyla; 3-4; 8-11; 6-14 ve 9-12 gün olarak saptanmıştır (Chugtai \& Khan, 1983). Giray (1961) bu değerleri sırasıyla 3-5; 9-14 ve 11-19 gün olarak belirtmiştir. Kavun sineğinin Ankara ili Kazan yöresi koşullarında doğada iki döl verdiği ve döl süresinin 32-41 gün arasında değiştiğini ve kavunun en önemli zararlısı olduğu vurgulanmıştır (Barış \& Çobanoğlu, 2013 a).

Kavun sineğinin zararlı olduğu devre larva dönemi olup, meyve kabuğunun içine konan yumurtadan çıkan larva hemen kabuktan meyvenin etli kısmına geçmekte ve kısa sürede çekirdek evine doğru ilerlemektedir. Meyvenin çekirdek evini delik deşik ederek beslenmektedir. Beslenme neticesinde tahrip edilen kavunun dokuları koyu kahve renk almakta ve meydana gelen koku kavun içerisine yayılmaktadır. Meyvenin tadı ve aroması bozulmaktadır. Olgunlaşan larvaların kavunları terk etmeleri esnasında açtıkları çıkış delikleri ile dokularda bozulma ve kokuşma, süratle kavunun her tarafına yayılmaktadır. Böylece zararları daha da artmakta, kavunlar artık yenilemeyecek duruma gelmekte ve pazar değerleri kaybolmaktadır. Kavun sineğinin doğrudan yaptığı zararın yanında, zarar görmüş kavunların çıkış deliklerinden fungal etmenler bulaşarak sekonder olarak da kavunların çürümesine neden olduğu belirlenmiştir (Giray 1961, Barış \& Çobanoğlu, 2013 a). Kavun sineği (M. pardalina)'nin kavunlarda Pakistan'da \%15 ila 60 civarında zarar yaptığı belirlenmiştir (Latif et al., 1987, Khan et al., 1992). Kontrol edilmediği yıllarda \% 80'lere varan kayıplara neden olabilmektedir. Buna rağmen bu zararlının biyolojisi ve savaşım alternatifleri konusunda dünyada çok az çalışma bulunmaktadır. Zararlı ile genel anlamda kimyasal yolla mücadele edilmektedir. Pakistan'da 1970'lerde salgın yapmış olan bu zararlı "invasive" yani saldırgan türler arasında nitelendirilmekte, zarar oranı yıllara ve ülkelere bağlı olarak çok farklı oranlarda ve çok önemli boyutlara ulaşabilmektedir (Stonehouse et al., 2006).

Kavun sineğinin Tephritidae familyası içerisinde en az bilinen meyve sineklerinden birisi olduğu belirtilmektedir (Freidberg, 1996). Zararlının ülkemizde tanımı, biyolojisi, zarar oranı ve konukçu tercihleri gibi biyolojisi üzerinde çok az veri bulunduğu, söz konusu zararlı üzerinde araştırmalara intiyaç olduğu bildirilmiştir (Giray, 1961; Barış \& Çobanoğlu, 2013 a, b; 2014). Belirtilen çalışmalara ilave olarak zararlı ile ilgili olarak gerek ülkemizde gerekse dünyada çok sınırlı sayıda veri bulunduğu ve biyolojisinin özellikle sabit koşullarda aydınlatılmasına intiyaç duyulduğu gözlenmektedir. Yürütülen bu çalışma ile gerek ülkemizde gerekse de 
dünyada biyolojisi ve savaşımı konusunda çok kısıtlı bilgiler bulunan Kavun sineğinin biyolojisi laboratuar koşullarında araştııımış zararlının yumurta, larva, prepupa, pupa, ergin dönemleri ile meydana gelen bireylerin eşey oranlarına ilişkin veriler elde edilmiştir.

\section{Materyal}

Bu çalışma Kavun sineği (M. pardalina)'nin üretimi amacı ile Zirai Mücadele Merkez Araştırma Enstitüsü Müdürlüğü iklim odalarından yararlanılmıştır. Denemeler $25 \pm 2{ }^{\circ} \mathrm{C}$ 'li ve $\% 65$ nem içeren 16 saat aydınlatmalı laboratuar koşullarında 20 tekerrürlü olarak yürütülmüştür. Ayrıca pupa süresinin hesaplanmasında doğadan toplanıp laboratuarda kültüre alınan bulaşık meyvelerden elde edilen 666 adet pupadan yararlanılmış olup, denemeler $25 \pm 2{ }^{\circ} \mathrm{C}$ ' sıcaklık; \%50 ve \% 65 olmak üzere iki farkı nem koşullarında çalışılmıştır. Laboratuar denemeleri 2009-2010 yılları arasında Kırkağaç kavun çeşidinde yürütülmüştür.

\section{Metot}

\section{Yumurta süresi}

Kavun sineğinin yumurta süresinin belirlenmesinde doğada $2 \times 2 \times 2 \mathrm{~m}$ ebadındaki kafeslerden yararlanılmıştır. Bu amaçla kafesler doğada yetiştirilmiş mevcut kavunlar üzerine yerleştirilerek sineklerin meyveyi enfekte etmeleri sağlanmıştır. Kafes içerisine 1 dişi 2 erkek sinek gelecek şekilde salım yapılmıştır. Erginler kafes içerisine bırakıldıkları andan itibaren günlük olarak kavun meyveleri kontrol edilmiş ve meyvelerde vuruk olup olmadığı izlenerek kayıtları tutulmuştur. Kavun sineğinin yumurta koymak amacı ile ovipozitörü ile meyve üzerinde açmış olduğu vuruk belirtileri gözle görülebilmektedir. Ancak bu belirtiler meyvenin fenolojik olarak gelişmesiyle birlikte giderek kapanmakta ve ileri dönemlerde fark edilememektedir. Kafesler içinde vuruk belirtileri gözlenen meyveler saplı olarak koparılarak laboratuara getirilmiş, içerisinde su bulunan plastik kaplara daldırımıştır. Vuruk olan bu meyveler üzerinde yumurta bırakılmış şüpheli alanlar günlük olarak kontrol edilmiştir. Kavun meyveleri üzerinde arazide vurukların gözlendiği ilk gün yumurtanın bırakıldığı birinci gün olarak kabul edilmiş ve gözlemler bu tarihten itibaren günlük olarak kavun kabuğu içinde yumurtalar izlenmiştir. Eğer yumurta kabuğu normal durumunu muhafaza ediyorsa yumurta açılmamış, yumurta kabuğu kırışmış ve pörsümüş ise açıldığı gün olarak değerlendirilmiştir. Bu aşamada genç larvanın yumurta kabuğunu terk ettiği anlaşılmıştır (Giray, 1961). Denemeler 20 tekerrürlü olarak yürütülmüştür.

\section{Yumurta + larva gelişme süreleri}

Kavun sineği ergin dişileri tarafından yumurta bırakılmasından itibaren meyve içinde olgunlaşan larvanın pupa olmak üzere kavunu terk ettiği tarih esas alınarak geçen süre birlikte değerlendirilmiş, yumurta + larva süresi toplam olarak belirlenmiştir. Bu amaçla doğada kavun bitkileri üzerine $2 \times 2 \times 2 \mathrm{~m}$ ebadında kafesler kurulmuştur. Her kafes içerisinde kavun bitkisinin bulunduğu ortama 1 dişi 2 erkek sinek gelecek şekilde salım yapılmıştır. Erginler kafes içerisine bırakıldıkları andan itibaren günlük olarak kavun meyveleri kontrol edilerek vuruk olup olmadığı belirlenmiştir.

Kavun sineğinin yumurta koymak amacı ile ovipozitörü ile meyve üzerinde açmış olduğu vuruk belirtileri gözle görülebilmektedir. Ik vuruk belirtileri saptandığı anda yumurtanın bırakıldığı ilk gün olarak kabul edilmiş, sonra bu meyveler saplı olarak koparılarak laboratuara getirilmiş ve sapları su bulunan plastik kaplara daldııımıştır. Meyveler günlük takip edilerek olgunlaşan larvanın pupa olmak üzere kavunu delerek geçen süre toplu olarak birlikte belirlenmiştir. Böylece Kavun sineği yumurtasının konması ve larvanın meyve içerisinde geçirdiği süre (yumurta ve larva süresi) hesaplanmıştır. Denemeler 20 tekerrürlü olarak yürütülmüştür.

Her bir larva dönemi süresini laboratuar koşullarında doğrudan tespit etmek için ortalama çapı $3 \mathrm{~cm}$ olan plastik petriler kullanıımışır. Bu amaçla genç dönemdeki larvanın beslenmesi için kavunun etli kısımlarından az miktarda rendelenerek hazırlanan besi ortamı üzerine larvalar yerleştirilmiştir. Denemeler $25{ }^{\circ} \mathrm{C}$ 'li ve \%65 nem içeren yetiştirme kabinlerinde ışıklandırma yapılmadan saat başı yapılan gözlemler ile karanlık bir ortamda 20 tekerrürlü olarak yürütülmüştür.

\section{Prepupa süresi}

Laboratuarda prepupa süresini belirlemek amacı ile araziden getirilen 1-2 delikli (larvanın pupa olmak için meyvede oluşturduğu çıkış deliği) meyvelerden yararlanılmıştır. Araziden toplanan bulaşık meyveler içerisinde 5 
cm kalınlığında elenmiş kum bulunan küvetlere alınmıştır. Saat başı yapılan kontroller ile toprağa pupa olmak üzere geçen olgun larvalar el değmeden kültüre alınmışır. Her bir küvet içerisine kavunu yeni terk etmiş 1 adet olgun larva bırakılmıştır. Olgun larva toprağa girdiği zaman fazla rahatsız edilmeden toprak yüzeyinden hafifçe açılmak sureti ile günlük olarak kontrolleri yapılmıştır. Denemeler 20 tekerrürlü olarak yürütülmüştür.

\section{Pupa süresi}

Laboratuarda pupa elde etmek, elde edilen pupaların açılım sürelerini belirlemek amacı ile araziden getirilen 1-2 larva giriş deliği (larva enfeksiyonu) olan meyvelerden yararlanılmıştır. Bu amaçla küvetlerin tabanı $5 \mathrm{~cm}$ kalınlığında elenmiş kum ile kaplanmış ve Kavun sineği larvası tarafından enfekte edilmiş meyveler araziden toplanarak plastik küvetlerde kum üzerine yerleştirilmiştir. Günlük olarak plastik küvet içerisindeki elenmiş kum kontrol edilerek, aynı günde meydana gelen pupaların kayıtları tutulmuştur (Şekil 1). Kültüre alınan pupaların $25 \pm 2{ }^{\circ} \mathrm{C}$ sıcaklık ve \%50 2 ; \%65 2 olmak üzere farklı iki nem koşullarında pupa açılma süreleri (gün) ve meydana gelen erginlerin dişi erkek birey oranları tespit edilmiştir. Pupa süresinin tespitinde 1. dölden elde edilen pupalardan meydana gelen erginlerden yararlanılmıştır. Denemenin değerlendirilmesinde 666 adet pupadan elde edilen veriler kullanılmıştır. Açılan pupalardan meydana gelen bireylerin dişi-erkek birey oranları belirlenmiştir.

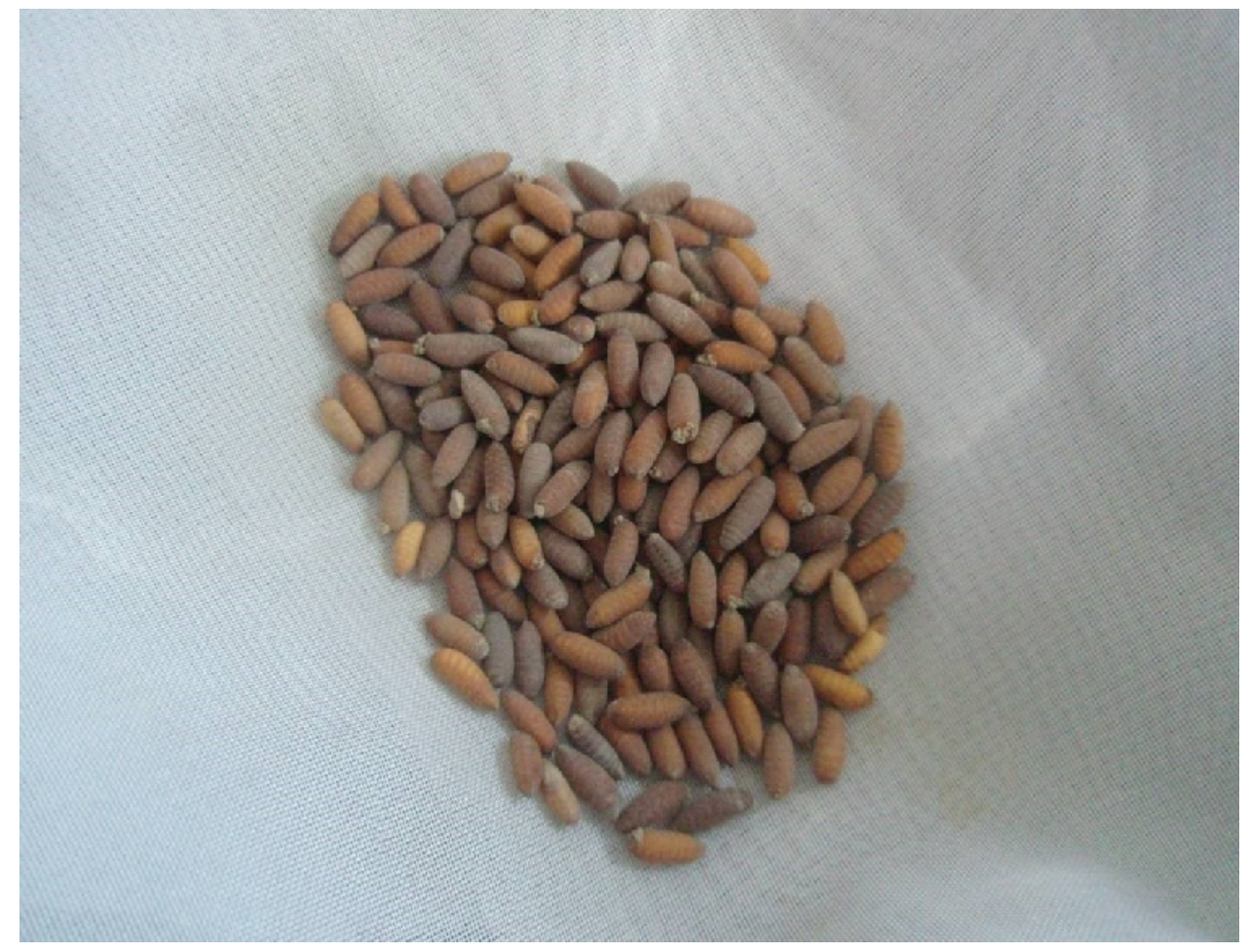

Şekil 1. Laboratuarda Kavun sineği (Myiopardalis pardalina) elde edilen pupalar (180 adet) (Orijinal).

\section{Kavun sineğinin pupa olduğu derinliklerin belirlenmesi}

Kavun sineğinin larvalarının toprakta pupa olduğu derinlikler laboratuar koşullarında belirlenmiştir. Bu amaçla elenmiş ve steril toprak kullanılmıştır. $20 \mathrm{~cm}$ derinliğe sahip olan plastik kavanozlar içerisine ağzına kadar toprak konularak araziden getirilen 1-2 delikli bulaşık meyveler bu toprakların üzerine yerleştirilmiştir. Bulaşık meyveler 1 hafta süre ile plastik kavanozlar üzerinde tutularak olgun larvaların toprağa geçmeleri sağlanmıştır. Bir haftanın sonunda yüzeyden başlayarak yavaş yavaş toprağın derinliğine doğru inilmiş ve pupaların bulunduğu derinlikler kayıt edilmiştir. Denemeler 20 tekerrürlü olarak yürütülmüştür. Tüm tekerrürlerden toplam 296 adet pupa elde edilmiştir. Tekerrürlerin pupa olma derinliklerine göre ortalaması (yüzde); tekerrürlere göre minimum maksimum pupa olma sayıları belirlenmiştir. Toprakta pupa olma derinlikleri toplam pupa sayısına oranlanarak yüzde olarak ifade edilmiştir. 


\section{Ergin ömrü}

Ergin ömrü tespiti için pupalardan yeni çıkan erginlerden bir dişi, bir erkek sinek $70 \mathrm{~cm}$ genişliğinde, 40 $\mathrm{cm}$ derinliğinde ve $50 \mathrm{~cm}$ yüksekliğinde kafeslere konulmuştur. Kafeslerin üst kısmı kapaklı ve telden yapılmış olup, ayrıca yan yüzeyine iki farklı havalandırma deliği açılmışır. Kavun sineğinin beslenmesine elverişli kavun meyveleri ile \%10 oranında hazırlanan ballı ve şekerli su eriyikleri pamuğa emdirilerek kafeslere bırakılmıştır. Günlük olarak meyveler, şekerli ve ballı su eriyikleri yenileriyle değiştirilmiştir. Laboratuarda 4000 lüx ışıklanma sağlayacak şekilde plastik kafesler raflara yerleştirilmiştir. Aydınlatma Philips (SON-T AGRO 400) marka 400 Watt'ık Sodyum içeren ışıklandırma ile sağlanmıştır. Bir günlük erginler ile denemeler başlatılmış ve günlük olarak kontroller ile kayıtları tutularak ölü olanlar kafeslerden alınmıştır. Denemeler 20 tekerrürlü olarak yürütülmüştür.

\section{Verilerin analizi}

Çalışmalarda laboratuarda tesadüf parselleri deneme deseni kullanılııştır. Yüzde olarak hesaplanan değerlere açı transformasyonu yapılmıştır. Varyans analizi uygulanan karakterlerin ortalamaları arasında farklılık görülmüş ise, bu ortalamalar arasındaki farklılıkları bulmak için Duncan testinden yararlanılmıştır. statistiki analizler SPSS 16.0 (SPSS, Chicago, IL, USA) paket programından yararlanılarak yapılmıştır.

\section{Araştırma Sonuçları ve Tartışma}

\section{Kavun sineğinin biyolojik dönemlerinin süreleri}

Kavun sineği (Myiopardalis pardalina)'nin bazı biyolojik özelliklerine ilişkin veriler Çizelge 1'de verilmiştir.

Çizelge 1. Kavun sineği (Myiopardalis pardalina)'nin laboratuarda $25 \pm 2{ }^{\circ} \mathrm{C}$ ve $\% 65$ nem koşullarında biyolojik dönemlerinin süreleri (Gün)

\begin{tabular}{ccccccc}
\hline \multicolumn{7}{c}{ Biyolojik özellikler [Ortalama \pm Standart hata (min - max)] } \\
\hline Yumurta & $\begin{array}{c}\text { Yumurta ve larva } \\
\text { gelişme } \\
\text { dönemleri }\end{array}$ & Prepupa & * Pupa Dişi & * Pupa Erkek & Ömür Erkek & Ömür Dişi \\
\hline $5.55 \pm 0.17$ & $14.70 \pm 1.26$ & $3.28 \pm 0.23$ & $20.59 \pm 0.31$ & $21.50 \pm 0.38$ & $08.05 \pm 0.22$ & $11.05 \pm 0.32$ \\
$(05.00-07.00)$ & $(12.00-17.00)$ & $(2.00-5.50)$ & $(18.00-24.00)$ & $(18.00-26.00)$ & $(06.00-10.00)$ & $(08.00-14.00)$ \\
$(n=20)$ & $(n=20)$ & $(n=20)$ & $(n=666)$ & $(n=666)$ & $(n=20)$ & $(n=20)$ \\
\hline
\end{tabular}

${ }^{*} \mathrm{~F}: 3.817 ; \mathrm{P}: 0.055$

\section{Yumurta süresi}

Çizelge ( 1 ) incelendiğinde laboratuarda yapılan çalışmalar sonucunda Kavun sineğinin yumurta açılma süresi 5.55 (5.00-7.00) ( $\mathrm{N=20)}$ gün olarak tespit edilmiştir. Laboratuar denemelerinde yumurtaların 1 ila 4 günde açılım göstermediği belirlenmiştir (Şekil 2). 


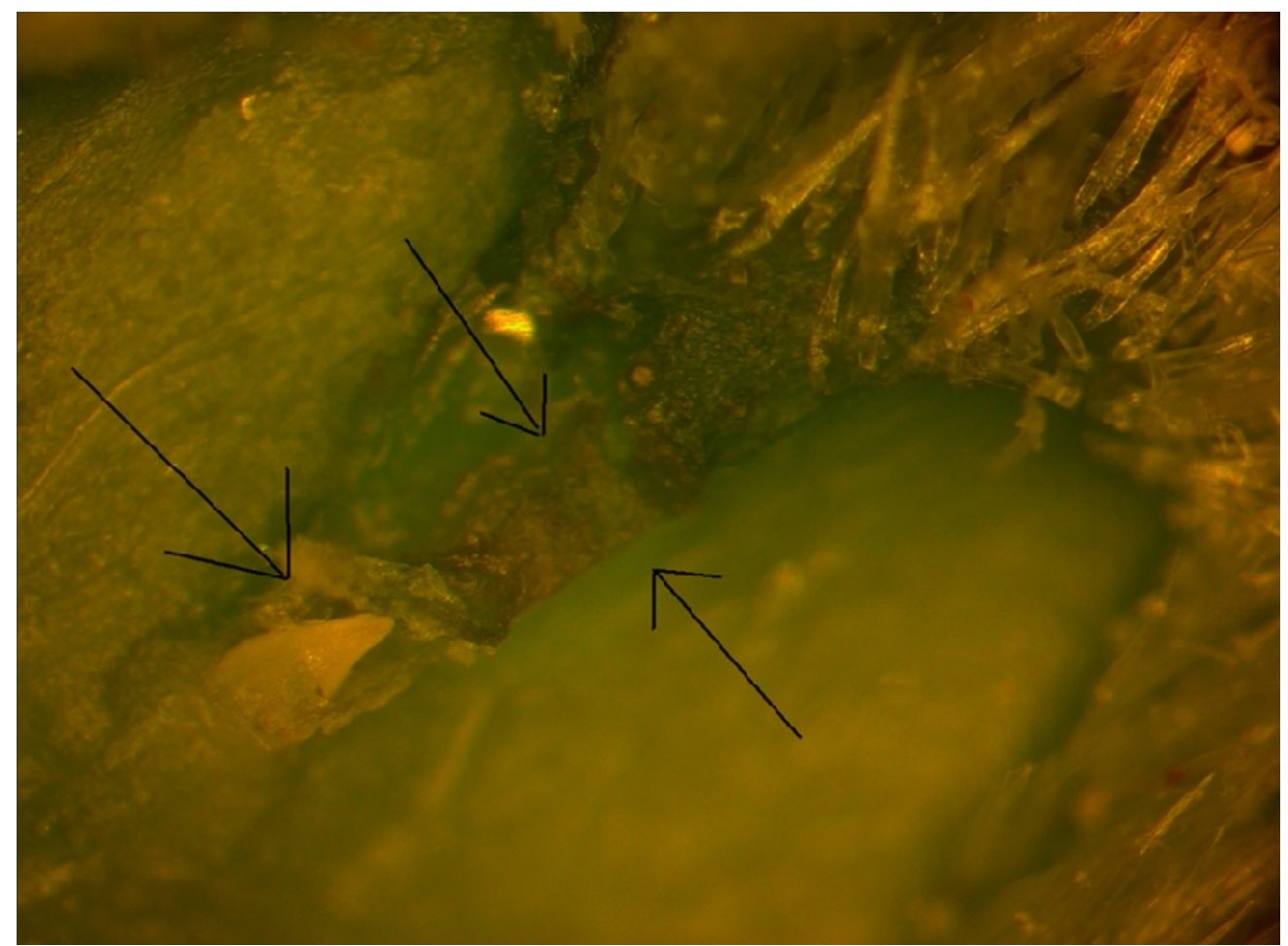

Şekil 2. Kavun sineği (Myiopardalis pardalina)'nin doku altına bırakılmış yumurtası ve dişinin yumurtayı koymak için meyve dokusunda açmış olduğu ovipozitör kanalı (Orijinal)

Giray (1961), Elazığ'da doğada yumurta açılma süresinin ortalama 3.95 (3.00-5.00) gün olduğunu belirlemiştir. Cleghorn (1891), Kavun sineğinin Hindistan'da biyolojisi üzerinde çalışmalarda bulunmuş, yumurta süresini 4 gün olduğunu belirlemiştir. Rekach (1930), M. pardalina'ın Transkafkasya kavunlarında çok zararlı olduğunu belirterek, yumurta süresinin 19 saat ile 7 gün arasında değiştiğini tespit etmiştir. Janjua et al. (1954), Baluchistan'da M. pardalina'ın yumurta süresini 4.26 gün olduğunu saptamıştır. Ankara ilinde laboratuar koşullarında yumurta açılım süresi 5-7 gün arasında değişmiştir.

\section{Yumurta ve larva gelişme süreleri}

Kavun sineğinin laboratuarda yumurta ve larva gelişime süreleri birlikte 14.70 gün (12.00-17.00) gün olarak belirlenmiştir (Çizelge 1). Barış \& Çobanoğlu (2013 a), Ankara ilinde doğa koşullarında yürüttükleri çalışmalarında yumurta ve larva süresini, Kavun sineğinin yumurta bırakmasından olgun larvanın meyveyi delerek terkettiği süreyi birlikte alarak değerlendirmişlerdir. Yumurta ve larva süresinin 15.5 ila 17.33 gün arasında olduğunu belirlemişlerdir. Demirdere (1956), Çukurova bölgesinde dişilerin yumurta koymalarından itibaren pupa oluncaya kadar geçmesi gereken sürenin 7 gün olduğunu, hava şartlarına bağlı olarak bu sürenin 11-12 güne kadar çıkabildiğini vurgulamıştır. Yurtdışında yapılan çalışmalarda ise Janjua et al. (1954), Pakistan'da larva süresinin 12-15 gün arasında değiştiğini, ortalama olarak ise 14.25 gün olduğunu belirtmişlerdir. Saparmamedova (2004), Türkmenistan'da Kavun sineğine ilişkin meyveye bırakılan yumurtanın açılmasıyla meydana gelen larvaların 11 - 23 gün boyunca kavunun etli kısmında beslendiğini saptamıştır.

Zararlının larva sürelerini tespit etmek için bir günlük larvalar denemeye alınmıştır. Bulaşık meyvelerden elde edilen genç dönemdeki larvalar alınarak kavun rendelenmiş petriler içerisinde kültüre alınmıştır. Her saat başı yapılan gözlemler sonucunda rendelenmiş kavunun kısa sürede kuruduğu (suyunu çektiği) belirlenmiştir. Ayrıca böyle bir ortam içerisinde de larvaların bulunmaya istekli olmadığı saptanmıştır. Normal koşullarda larva meyve içerisinde galeriler açarak ilerlemektedir. Larvaların doğal olarak zararlı olduğu galerilerden çıkarıldıklarında rahatsız oldukları gözlenmiştir. Sonuçta larvanın taze rendelenmiş kavun ortamında durmaya ya da bulunmaya istekli olmadığı gözlenmiştir. 
Açılan yumurtalar mikroskop altında incelenmiş olmasına rağmen larva tespit edilememiştir. Kavun kabuğunun altına bırakılan ve açılmış olduğu tespit edilen (açılmış yumurtayı kabukta görmek mümkün olmaktadır) yumurtaların bulunduğu alanlar bir iğne yardımı ile kavunun etli kısmına doğru dikkatli bir şekilde açılarak larvalar aranmıştır. Larvanın çok küçük, şeffaf ve meyve etine yakın bir renkte olması nedeniyle larva dönem sürelerinin ayrı ayrı belirlenmesi mümkün olmamıştır. Bu sebeplerle Kavun sineğinin larva dönem süreleri ayrı ayrı tespit edilememiştir. Larvanın meyve içerisindeki toplam kalış süresinin dönem uzunluğu belirlenmiştir. Ülkemizde yapılan çalışmalarda ise Giray (1961), laboratuarda larva sürelerini ayrı ayrı belirlemiştir. Birinci larva süresini 2.32 (2.00-3.00) gün, ikinci larva süresini 3.93 (3.00-5.00) gün, üçüncü ve son larva süresini 5.53 (4.00-7.00) gün, toplamda ise bu süreyi ortalama olarak 11.69 gün olarak belirlemiştir.

\section{Prepupa süresi}

Denemeler sonucunda kavunu yeni terk etmiş olgun larvanın 2 ila 5 saat süre ile gezindiği tespit edilmiştir. Ortalama olarak olgun larvanın hareket süresi 3.18 \pm 0.18 (2.00-5.00) saat olarak belirlenmiştir. Daha sonra olgun larva büzüşerek hareketsiz kalmakta ve prepupa olmaya başlamaktadır. Prepupa süresi ortalama olarak 3.28 (2.00-5.50) saat belirlenmiştir. Bu dönemde artık hareket bitmekte ve pupa görüntüsü almaya başlamaktadır. Ik pupa olduğunda rengi beyazımsı sarı ve saydam renkte olup, renk giderek koyulaşmaktadır (Şekil 3). Giray (1961), bu sürenin 12 ile 15 saat arasında değiştiğini belirtmiştir.

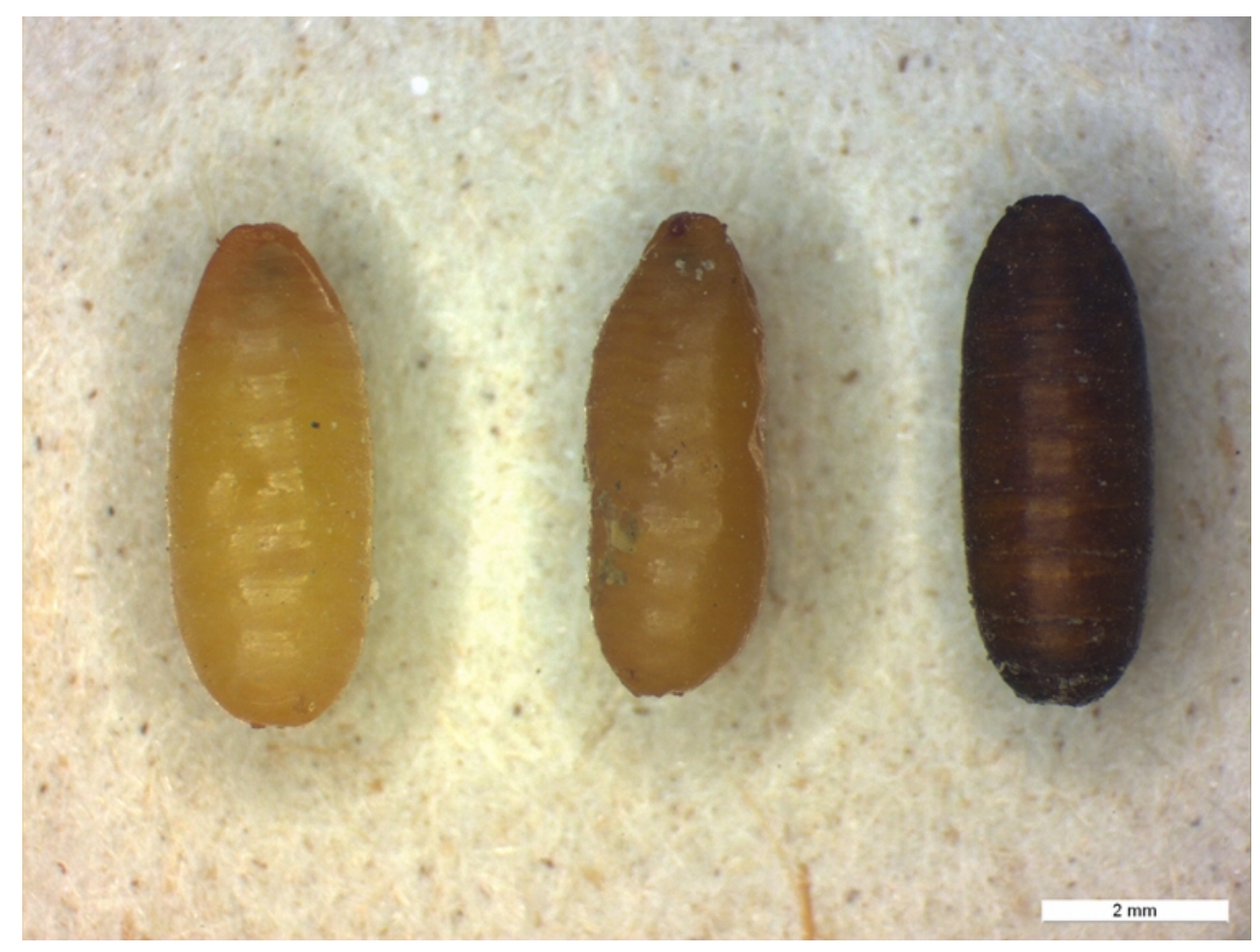

Şekil 3. Kavun sineği (Myiopardalis pardalina) pupasındaki renk değişimi (Orijinal)

\section{Pupa süresi ve cinsiyetler oranı}

Laboratuar koşullarında Kavun sineğinin dişi ve erkek pupa gelişme süreleri incelendiğinde aradaki farkın önemli olduğu saptanmıştır (Çizelge 1). Dişlerde pupa süresi ortalama olarak 20.59 (18.00-24.00) gün, erkeklerde ise bu süre 21.50 (18.00-26.00) gün olarak belirlenmiştir (F: 3.817; P: 0.055).

\section{Pupa açılma oranı}

Laboratuar ortamında pupa açııma oranını tespit etmek amacıyla iki farklı çalışma yapılmıştır. Birinci yapılan laboratuar çalışmasından elde edilen 304 adet pupadan 22 adet ergin birey elde edilmiştir. kinci defa yapılan laboratuar çalışmasından ise 362 adet pupa kültüre alınmış, 44 adet pupa açılmıştır. Her iki çalışmada da yürütülen çalışmalar sonucunda pupa açılımının \% 10.00 olduğu tespit edilmiştir. Yapılan çalışmalar sonucunda iki farklı nemde (\% 50-65) pupaların açılma süreleri bakımından farklılık tespit edilmemiştir (F: 0.404; 
P:0.528). Ele alınan iki farkı neme (\% 50 ve 65) bağlı olarak nem cinsiyet interaksiyonu saptanmamıştır (F: 0.864; P:0.356). Diğer bir ifadeyle çalışma süresince iki farklı nem koşullarına tabii tutulan pupaların açılma süreleri ve meydana gelen erkek-dişi birey oranı bakımından farklıı̆ın önemli olmadığı belirlenmiştir.

\section{Cinsiyetler oranı}

Laboratuar ortamında cinsiyet oranını tespit etmek amacıyla iki farklı çalışma yapılmıştır. Ik yapılan denemeler sonucunda elde edilen 22 adet erginin 12'si dişi, geriye kalan 10'unu erkek olduğu belirlenmiştir. kinci yapılan laboratuar çalışmasında ise toplam 44 adet erginin 25 adedi dişi, geriye kalanlar ise erkek birey olduğu saptanmıştır. Cinsiyet oranı \% 56 olarak saptanmıştır (Dişi /Dişi+Erkek).

Barış \& Çobanoğlu (2013 a), Ankara ilinde tarla koşullarında yürüttükleri çalışmalarında Kavun sineğinin 2009 yılında birinci dölde pupa süresi ortalama olarak 21.67 (20.00-23.00) gün, 2010 yılında birinci dölde pupa süresi ortalama olarak 19.40 (16.00-22.00) gün olarak tespit etmişlerdir. Giray (1961), Elazığ'da pupa süresinin 11 ila 19 gün arasında değiştiğini, ortalama olarak 14.58 gün sürdüğünü belirlemiştir. Demirdere (1956) Çukurova da pupa süresinin 11 ila 17 gün arasında değiştiğini tespit etmiştir. Janjua et al. (1954), Pakistan'da Kavun sineği pupa süresinin 14 ila 20 gün arasında değiştiğini, ortalama olarak 16.72 gün sürdüğünü belirlemişlerdir. Saparmamedova (2004) Türkmenistan'da Kavun sineğinin pupa süresinin 9 ila 15 gün arasında değiştiğini ayrıca larvaların \%8 - 15’inin meyvenin etli kısmında pupa olduğu bildirmiş̧tir.

\section{Pupa olma derinliği}

Kavun sineğinin toprakta pupa olduğu derinlikler Çizelge (2)' de verilmiştir.

Çizelge 2. Kavun sineği (Myiopardalis pardalina)'nin laboratuar koşullarında toprakta pupa olma derinliği (\%) $(N=20)$

\begin{tabular}{cccccccc}
\hline \multicolumn{7}{c}{ Toprak derinliği $(\mathbf{c m})$ [Ortalama \pm Standart hata (min - max)] } \\
\hline $1-2$ & $3-4$ & $5-6$ & $7-8$ & $9-10$ & $11-12$ & $13-14$ & $15-16$ \\
& & & & & & & \\
\hline $32.10 \pm 2.42 \mathrm{a}$ & $25.00 \pm 2.35 \mathrm{a}$ & $13.56 \pm 2.34 \mathrm{c}$ & $9.19 \pm 1.79 \mathrm{bc}$ & $6.78 \pm 1.42 \mathrm{~cd}$ & $5.87 \pm 1.41 \mathrm{~cd}$ & $4.35 \pm 1.17 \mathrm{~cd}$ & $3.15 \pm 0.85 \mathrm{~d}$ \\
$(12.50-50.00)$ & $(0.00-40.00)$ & $(0.00-35.71)$ & $(0.00-23.07)$ & $(0.00-18.18)$ & $(0.00-20.00)$ & $(0.00-18.18)$ & $(0.00-10.00)$ \\
\hline
\end{tabular}

$F: 21.69 ; P: 0.00$

Kavun sineğinin toprağın 1-2 cm'den, 15-16 cm derinliğe kadar pupa olabildiği saptanmıştır (Çizelge 2). Zararlının 1-2 cm toprak derinliğinde en yüksek oranda \%32.10 (12.50-50.00), en düşük oranda ise 15-16 cm'de \%3.15 (0.00-10.00) oranında pupa olduğu belirlenmiştir. Kavun sineğinin pupa olma oranı toprak derinliğine bağlı olarak giderek azalmıştır. Bu çalışma ile Kavun sineğinin \%70.66'sı toprağın ilk $6 \mathrm{~cm}$ derinliğinde pupa olmayı tercih ettiği saptanmıştır. Özellikle en yüksek oranda toprağın 1-2 cm'sinde, yani yüzeye çok yakın bir şekilde pupa olduğu belirlenmiştir. Hatta toprağın üzerindeki meyveler kaldıııdığında yüzeye yakın ve hemen yüzeyin altındaki pupaları görmek mümkün olmuştur (Şekil 4). 


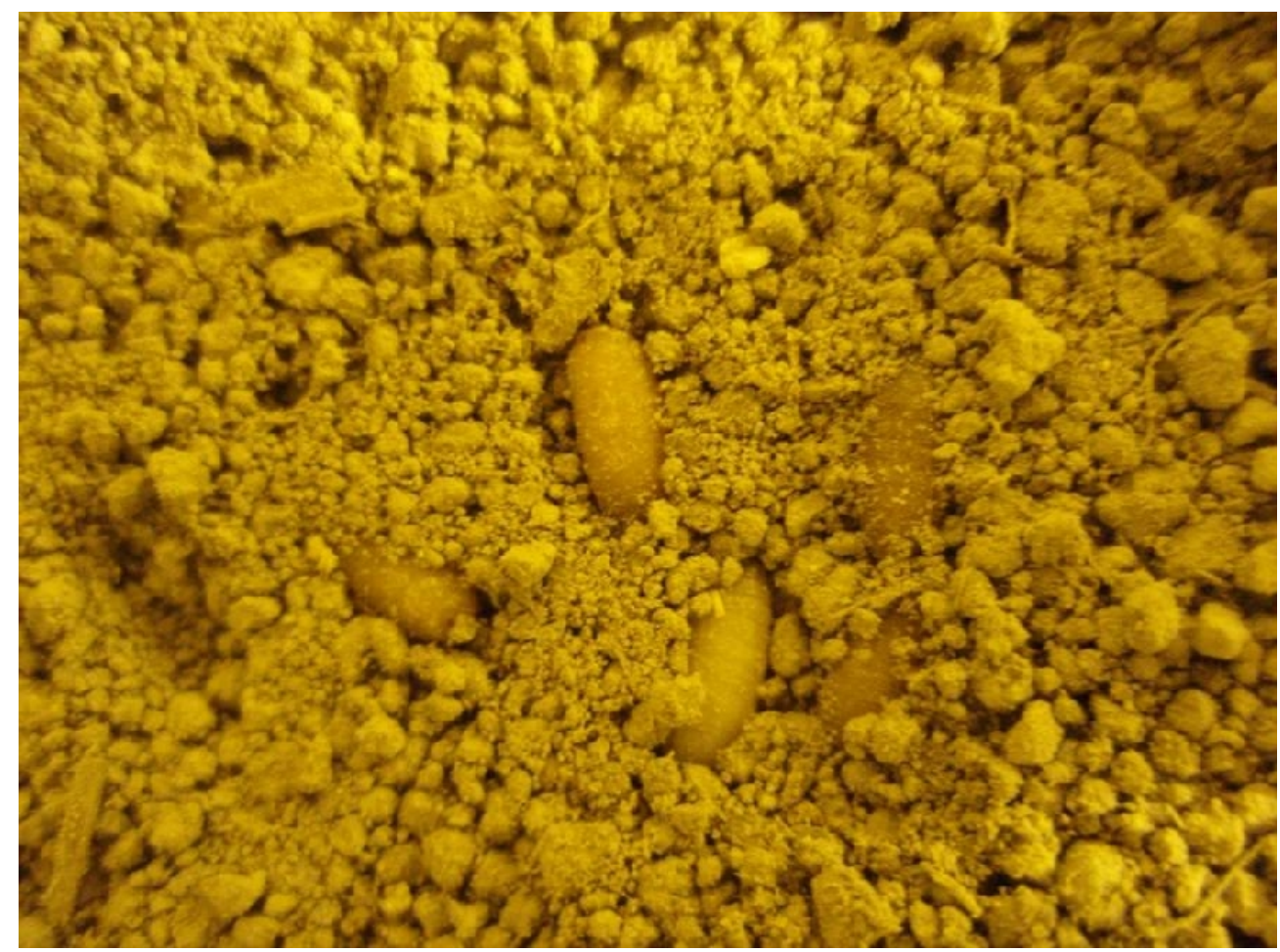

Şekil 4. Kavun sineği (Myiopardalis pardalina)'nin pupaları (Orijinal)

Barış \& Çobanoğlu (2013 a), Ankara ilinde Kavun sineğinin pupa olduğu derinliklerin doğada toprağın 1-2 cm'sinden 15-16 cm'sine kadar değiştiğini ve en yüksek oranda toprağın ilk 5-6 cm'sini tercih ettiklerini belirlemişlerdir.

Giray (1961), Elazığ'da Kavun sineğinin toprak yapısına bağlı olarak 1 ila $14 \mathrm{~cm}$ derinlikleri arasında pupa olabileceğini, en fazla 5-6 cm'de pupa olduğunu belirtmiştir. Demirdere (1956), Çukurova'da toprağın nemine bağlı olarak 3.5 ila $4.5 \mathrm{~cm}$ 'de pupa olduğunu, hatta $7 \mathrm{~cm}$ 'ye kadar inebildiklerini tespit etmiştir. Janjua et al. (1954), Pakistan'da Kavun sineğinin genellikle $5 \mathrm{~cm}$ (2 inch) civarında pupa olduğunu saptamışlardır. Saparmamedova (2004), Türkmenistan'da olgun larvanın toprağın 1 ila $14 \mathrm{~cm}$ derinliğinde pupa olabildiğini belirtmiştir. Stonehouse et al. (2006), pupaların farklı derinliklerde görüldüğünü ve $50 \mathrm{~cm}$ derinlikteki topraklardan dahi ergin çıkışı olabildiğini belirtmektedirler.

\section{Ergin ömrü}

Kavun sineğinin ergin ömrü dişilerde ortalama 11.05 (8.00-14.00) gün olarak saptanmıştır $(\mathrm{N}=20$ ㅇ ㅇ). Erkeklerde ise bu süre ortalama 8.05 (6.00-10.00) gün olarak belirlenmiştir ( $\left.\mathrm{N}=20 \sigma^{\pi} \sigma^{\pi}\right)$ (Çizelge 1$)$. 


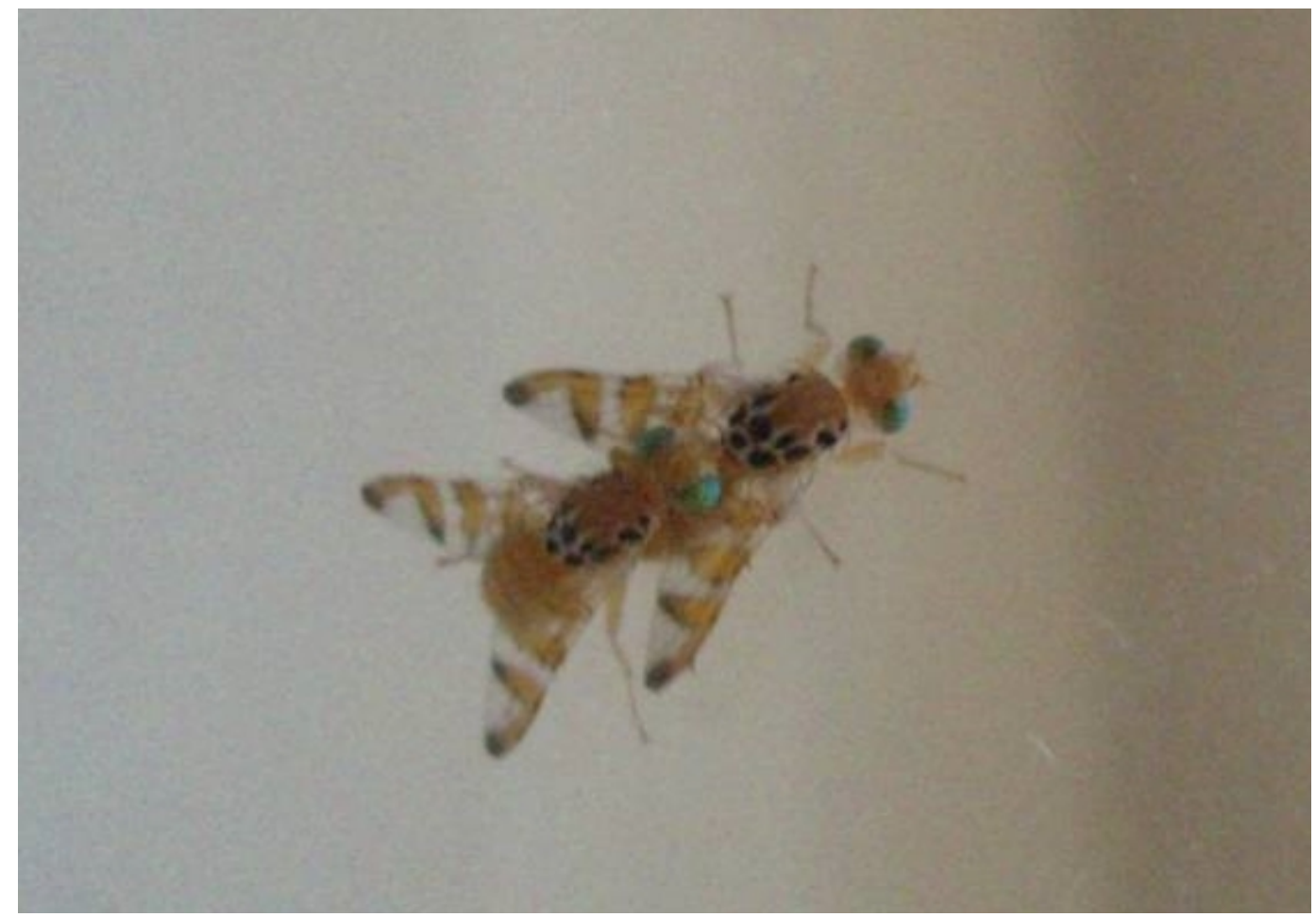

Şekil 5. Kavun sineği (Myiopardalis pardalina)'nin $25 \pm 2{ }^{\circ} \mathrm{C}$ 'li ve \%65 nem içeren 16 saat aydınlatmalı laboratuvar koşullarında çiftleşmekte olan erginler (Orijinal)

Giray (1961), ergin ömür uzunluğunu dişilerde 15-24 gün, erkeklerde ise 11-12 gün civarında olduğunu belirtmiştir. Barış \& Çobanoğlu (2013 a), doğada Kavun sineğinin ergin ömrünü dişilerde ortalama olarak 17.67 ile 18.21 gün arasında değiştiğini, erkeklerde ise ortalama 12.33 ile 12.75 gün sürdüğünü belirtmiştir. Laboratuar koşullarında elde edilen dişi ve erkek ömür uzunlukları her iki çalışmadan elde edilen sonuçlardan daha kısa olarak bulunmuştur. Araştırıcıların doğadan elde ettikleri verilere göre laboratuarda ergin ömrünün daha kısa olması beklenen bir sonuçtur.

M. pardalina'nın biyolojisi Kafkasya, ran ve Türkmenistan da doğal koşullarda belirlenmiştir. Zararılı kışı pupa olarak toprakta geçirmekte ve Mayıs ayında ilk ergin çıkışlarının gerçekleştiği belirtilmektedir. Dişi başına ortalama 100 yumurta konmaktadır. Larva süresi 8-18 gün, pupa süresinin ise 13-20 gün sürdüğü ifade edilmektedir (INKTO 1957, Manukyan, 1974, Garcia et al. 2002).

M. pardalina erginlerinin yumurta koyma tercihleri konusunda da bazı veriler bulunmaktadır. Tatı kavun çeşitleri ile taze ve bütün kavunların; ekşi, beklemiş ve yarım kavunlara göre daha çok tercih edildiği ifade edilmektedir (Alies Van Sauers - Muller, 2005). Kavun sineğinin yumurta koymasında, koku ve görünümün etkili olduğu, zararlının yumurta koymak için uygun meyveyi seçmesinde dişinin önceki deneyimlerinin de önemli olduğu vurgulanmaktadır. Dişilerin yumurta koymak için en uygun bitkileri tanıma yetenekleri olduğu belirtilmektedir. Meyvelerin besin değeri, biyokimyasal yapısı özellikle larvaların faaliyetlerini yeterli düzeyde gösterebilmesi için hayati önemde olduğu saptanmıştır (Cooley \& Prokopy, 1986; Prokopy \& Duan, 1998).

ran'da zararlı ile savaşımda kimyasal mücadeleye alternatif olarak; steril erkek metoduna dayalı genetik mücadele olanakları araştııımıştır. Dişinin bir kez çiftleşmesi halinde bu yöntemin başarı şansının oldukça yüksek olması nedeniyle laboratuar koşullarında çiftleşme davranışları üzerinde çalışılmış ve dişinin ömrü süresince ortalama $5.83 \mathrm{kez}$ çiftleştiği belirlenmiştir. Çiftleşmede besin bulunup bulunmamasının önemli olmadığı vurgulanmıştır. Bu durumun diğer Tephritid'lerde sıklıkla görülen bir durum olmadığı belirtilmektedir. $M$. pardalina dişisinin birden fazla çiftleşmesi nedeniyle kısır erkek salımının bu zararlı savaşımında kullanılmasının mümkün olmadığı, cinsel çekicilerin dişiyi çekmede başarılı olabileceği ve IPM programlarında önerilebileceği vurgulanmaktadır (Morteza \& Mohammadipour, 2014). 
Kazakistan Cumhuriyeti, M. pardalina karşı pek çok Asya ülkesi ve Türkiye'den ithal edilen ürünler için karantina listesi hazırlamış olup kavun ithal edilmesi halinde tek tek bireysel olarak paketlenme şartı aramaktadır (Anonymous, 2010).

Sonuç olarak M. pardalina'nın laboratuar koşullarında biyolojik parametrelerinin belirlenmesi ile zararııın yumurta, yumurta ve larva gelişme süreleri, prepupa, pupa ve ergin ömrü ile pupa olduğu derinlikler ilk kez bu çalışma ile elde edilmiştir Dişi ve erkelerde pupa açılım süreleri bakımından farkın önemli olduğu (F: 3.817; P:0.055) saptanmıştır. Ancak çalışmada yürütülen iki farklı neme (\% 50-65) bağlı olarak pupa açılım süreleri ve meydana gelen cinsiyetler bakımından aradaki farkın önemli olmadığı belirlenmiştir. Cinsiyet oranı 0.56 /dişi olarak belirlenmiştir. Kavun sineğinin laboratuvar koşullarında 1 ila $16 \mathrm{~cm}$ arasında arasındaki toprak derinliğinde pupa olabildiği belirlenmiştir. Zararlının pupa olma derinliğinin ilk cm'lerden başlayarak toprak derinliğine bağlı olarak azaldığı saptanmıştır. Kavun sineğinin laboratuar koşullarında larva süreleri ayrı ayrı tespit edilememiştir. Ayrıca zararlının laboratuar koşullarında pupa açılımının \% 10 civarında olduğu, çiftleşme gözlenmesine rağmen yumurta bırakmadığı saptanmıştır $M$. pardalina'nın biyolojisi ve davranışları ile konukçu tercihlerinin belirlenmesi ilgili olarak daha detaylı çalışmalara intiyaç olduğu düşünülmektedir. Zararlının 2013 yılında EPPO alarm listesine girmesi, karantinaya tabii olması, biyolojisinin çalışımasının çok zor olması ve mücadelesinin güç olması nedeniyle savaşım alternatifleri üzerinde araştııımasına intiyaç vardır ve konu üzerinde yapılan çalışmalar önemli olacaktır.

\section{Yararlanılan Kaynaklar}

Abdullah K. \& A. Latif, 2001. Studies on baits and dust formulations of insecticides against fruit fly (Diptera: Tephritidae) on melon (Cucumis melo) under semi arid conditions of D. I. Khan. Pak. J. Biol. Sci., 4: 334-335.

Abdullah K, M. Akram \& A.A. Alizai, 2002. Nontraditional control of fruit flies in guava orchards in D. I. Khan. Pak. J. Agric. Res., 17:195-196.

Alies Van Sauers-Muller, 2005. Host Plants of the Carambola Fruit Fly, Bactrocera carambolae Drew \& Hancock (Diptera: Tephritidae), in Suriname. South Am. Neotrop. Entomol., 34(2):203-214.

Alkan, B., 1946. Tarım Entomolojisi. T.C. Tarım Bakanlığı Ankara Yüksek Ziraat Enstitüsü Ders Kitabı. 31. A.Y.Z.E. Basımevi Ankara, $156 \mathrm{~s}$.

Anonymous, 2013. Tarımsal Yapı (Üretim, Fiyat, Değer). T.C. Başbakanlık Devlet statistik Enstitüsü, ISSN 1300-1213.

Anonymous, 1961. Myiopardalis pardalina. [Distribution map]. Distribution Maps of Plant Pests. June, Map 124.

Anonymous, 2010. Main Phytosanitary Specifications. Kazakhistan Customs Union Commission on June $18,2010$.

Barış, A. \& S. Çobanoğlu, 2013a. Kavun sineği [Myiopardalis pardalina (Bigot, 1891) (Diptera: Tephritidae)]'nin Ankara linde Biyolojisi Üzerinde Araştırmalar. Türkiye Entomoloji Dergisi, (3) 37:293-304.

Barış, A. \& S. Çobanoğlu, 2013b. Kavun sineği [Myiopardalis pardalina (Bigot, 1891) (Diptera: Tephritidae)]'nin Farklı Kavun Çeşitlerindeki Zarar Oranının Belirlenmesi. Bitki Koruma Bülteni, 53(1):43-49.

Barış, A. \& S. Çobanoğlu, 2014. Kavun sineği [Myiopardalis pardalina (Bigot, 1891) (Diptera: Tephritidae)]'nin Bazı Morfolojik Özellikleri. Gaziosmanpaşa Üniversitesi Ziraat Fakültesi Dergisi, 31 (2): 72-79.

Bigot, J.M.F., 1891. The Baluchistan Melon Fly. (Carpomyia pardalina,_et_,nov.sp.).Indian Museum Notes 2: 51. www.sel.barc.usda.gov/diptera/tephriti/Carpomya/pardalin. 31.12.2008.

Bodenheimer, F.S., 1941. Türkiye'de Ziraate ve Ağaçlara Zararlı Olan Böcekler ve Bunlarla Savaş Hakkında Bir Etüt. Bayur Matbaası, Ankara, 207s.

Chugtai G.H. \& L. Khan, 1983. Studies on the biology and chemical control of melon fly, Myiopardalis pardalina Bigot. Pakistan Entomologist, 5(1-2): 17-20. 
Cleghorn, J., 1891. The Baluchistan Melon Fly. Carpomyia pardalina, Bigot Indian Museum Notes, Vol. II, No. 7, 1891-93, pp. 51, (Web adresi: www.archive.org/stream/reportonparasiti00newsrich/reportonparasiti00newsrich djvu.txt), (Erişim tarihi:17.04.2015).

Cooley S.S. \& R.J. Prokopy, 1986. Learning in oviposition site selection by Ceratitis capitata flies. Entomologia Exp. Appl. Dordrecht 40:47-51.

Demirdere, A., 1956. Kavun ve karpuzlarda Myopardalis pardalina (Kavun sineği) ve mücadelesi. T.C. Ziraat Vekaleti Ziraat Mücadele Enstitüsü Yayınları. Adana No.15.

EPPO, 2013. Myiopardalis pardalina (Dip. Tephritidae) Baluchestan melon fly. (Web adresi:www.eppo.int/quarantine/alert lit/insects/Myiopardalis pardalina.htm, ( Erişim tarihi: 17.04.2015)

Freidberg, A. \& J. Kugler, 1989. Fauna Palaestina, Insecta IV Diptera: Tephritidae. The Israel Academy of Sciences and Humanities, Jerusalem. 212p.

Freidberg, A., 1996. The Israeli Tephritid fauna revisited. Abstract of paper presented at the 8th conference of the Entomological Society of Israel, Bet Dagan. Phytoparasitica, 24:2-3.

Garcia, L., N.K. Saparmamedova \& A. Arazmuradov, 2002. Baluchistan Melon Fly, Carpomyia pardalina, in Turkmenistan. Unpublished presentation. Winrock International.

Giray, H., 1961. Elazığ ve çevresinde Kavun sineğinin biyolojisi üzerinde incelemeler. Ege Üniversitesi Ziraat Fakültesi Yayınları, No:43. zmir.

Janjua, N.A., 1954. Biology of the melon fly, Myiopardalis pardalina Big. (Trypetidae), in Baluchisatn. Indian Journal Entomology, 16: 227-233.

INKTO, 1957. Myiopardalis pardalina. Insects Not Known to Occur in the United States (INKTO). APHIS-USDA.

Kapoor V.C., D.E. Hardy, M.L. Agarwal \& J.S. Grewal, 1980. Fruit fly (Diptera:Tephritidae) systematics of the Indian subcontinent. Export Indian Publisher Jullundur, India 3:59-61.

Khan, L., C. Inayatullah \& M. UI-Haq, 1992. Control of melon fruit fly Dacus cucurbitae (Diptera: Trypetidae ) on melon in Pakistan. Tropical Pest Management, 38: 261-264.

Latif, A., N.K. Marwat \& N. Hussain,1987. Suppression of population and infestation of Dacus spp. fruit flies through the use of protein hydrolysate. Sarhad Journal of Agriculture (Pakistan), 3(4): 509-513.

Manukyan, G., 1974. Reducing fruit damage by Myiopardalis pardalina. Kartofel' i Ovoshchi 7: 37-38. (in Russian).

Morteza M.F. \& A. Mohammadipour, 2014. Mating Frequency, Duration and Time in Baluchistan Melon Fly Myiopardalis pardalina (Bigot) (Diptera: Tephritidae). Jordan Journal of Biological Sciences. 7 (3): $211-215$.

Rauf, I., N. Ahmad, S.M. Masoom S. Rashdi, M. Ismail \& M. Hamayoon Khan, 2013. Laboratory studies on ovipositional preference of the peach fruit fly Bactrocera zonata (Saunders) (Diptera: Tephiritidae) for different host fruits. African Journal of Agricultural Research. 8(15):1300-1303.

Rekach, V.N., 1930. Studies on biology and control of the melon-fly Carpomyia (Myiopardalis) caucasica Zaitz In Russian, with English and Azerbaijan summaries. Bull Azerbaijan Central Agric Plantbreeding Exp Sta Div Ent., 9:1-32.

Panhwar, F., 2005. Mediterranean fruit fly (Ceratitis capitata) attack on fruits and its control in Sindh, Pakistan. Publisher: Digital Verlag. GmbH, Germany, www.chemlin.de.

Prokopy, R.J. \& J.J. Duan, 1998. Socially facilitated egglaying behavior in Mediterranean fruit flies. Behav. Ecol. Sociobiol, Heidelberg, 42 (2):117-122.

Saparmamedova, N.K., 2004. To the knowledge of the melon fly, Myiopardalis pardalina Big. (Diptera, Tephritidae) in Turkmenia. Entomologicheskoe Obozrenie, 83(3): 517-520.

Stonehouse J.M., R. Mahmood, A. Poswal, J. Mumforda, K.N. Baloch, Z.M. Chaudhary, A.H. Makhdum, G. Mustafa \& D. Huggett, 2002. Farm field assessments of fruit flies (Diptera: Tephritidae) in Pakistan: distribution, damage and control. Crop Protectection, 21:661-669. 
Stonehouse J., S.M. Sadeed, A. Harvey \& G.S. Haiderzada, 2006. Myiopardalis pardalina in Afghanistan. Proceedings of the $7^{\text {th }}$ International Symposium on Fruit Flies of Economic Importance,10-15 September 2006, Salvador, Brazil pp. $1-12$. 